\title{
ELEVAÇÃO DA CAPACIDADE DE COMPRESSÃO UTILIZANDO VÁLVULA GUIDE-VANES PARA CONTROLE DE CAPACIDADE*
}

Samuel Vasconcellos ${ }^{1}$

\section{Resumo}

Existem vários tipos de compressores centrífugos de gás, mas em todos o sistema de controle de capacidade influencia diretamente a performance do compressor e também a capacidade máxima de compressão do mesmo. O Controle de Capacidade do Compressor por ser realizado a partir de válvulas tanto na sução bem como na descarga em forma de vent ou mesmo uma válvula em forma de recirculação. Todos os sistemas operam como forma de controle de capacidade mas o mais eficiente é por meio de controle por uma válvula na sucção do compressor, pois tanto a recirculação como um vent na descarga não reduzem o consumo de energia elétrica de forma eficiente pela vazão entregue. Neste trabalho trataremos particularmente de um controle de capacidade por meio de válvulas de sucção em compressores de nitrogênio centrífugos procurando uma forma mais eficiente de compressão e também elevar a capacidade de compressão.

Palavras-chave: Compressores centrífugos; Controle de capacidade.

\section{CAPACITY COMPRESSION IMPROVEMENT USING GUIDE-VANE VALVE TO CAPACITY CONTROL}

\section{Abstract}

There are several centrifugal gas compressors models, but all the capacity control system has direct influence on the compressor performance and also on the compression capacity. The Compressor capacity control can be done by valves on the suction, on the discharge like vents or even as a recirculation. All these tree systems operate well but the most efficient is by using a valve on the suction because the vent or recirculation doesn't reduce the electrical power efficiently by the total gas flow. In this job we are going to work with the capacity control using a suction valve in centrifugal nitrogen compressors looking for a more efficient way to operate and increase the compression capacity

Keywords: Centrifugal compressor; Capacity control. 


\section{INTRODUÇÃO}

Todo compressor centrífugo possui algum sistema de controle de capacidade, mas dependendo do tipo de controle podemos interferir diretamente na performance do compressor.

O compressor em estudo que foi utilizado como base deste trabalho é um compressor centrífugo de nitrogênio gás que tem de design as seguintes características:

- Pressão Sucção: 15 psia;

- Pressão de Descarga: 125 psia;

- Temperatura de Alimentação: $25^{\circ} \mathrm{C}$;

- Capacidade de Compressão: $15.000 \mathrm{Nm}^{3} / \mathrm{h}$;

- Consumo de Energia Elétrica: 1677 KW/h;

- Número de Estágios: 3;

- Eficiência Adiabática: $80 \%$.

O compressor de nitrogênio possuía uma válvula borboleta de 16 " na sucção para controle de capacidade, a mesma possuía posicionador eletrônico atuando de forma automática controlando a capacidade do compressor por meio da pressão de descarga do mesmo, sendo assim quando a pressão era elevada a válvula restringia o fluxo e a medida que a pressão reduzi-se a mesma abria liberando mais fluxo para compressão.

O Compressor operava com a seguinte característica:

- Pressão Sucção: 15,5 psia;

- Pressão de Descarga: 102 psia;

- Temperatura de Alimentação: $20^{\circ} \mathrm{C}$;

- Capacidade de Compressão: 15.313 Nm³/h;

- Consumo de Energia Elétrica: $1712 \mathrm{KW} / \mathrm{h}$;

- Número de Estágios: 3;

- Eficiência Adiabática: $69 \%$.

É possível verificar que mesmo operando com a pressão de descarga $18 \%$ inferior ao design a vazão de operação estava em apenas $2 \%$ acima.

\section{MATERIAIS E MÉTODOS}

Para a realização do projeto foram estudados os efeitos de trabalho de válvulas automáticas e suas respectivas características bem como seus efeitos em compressores centrífugos.

A válvula utilizada no compressor para controle de capacidade era uma válvula borboleta automática com posicionador de 16" de diâmetro, modelo este de válvula similar ao representado na figura 1. 


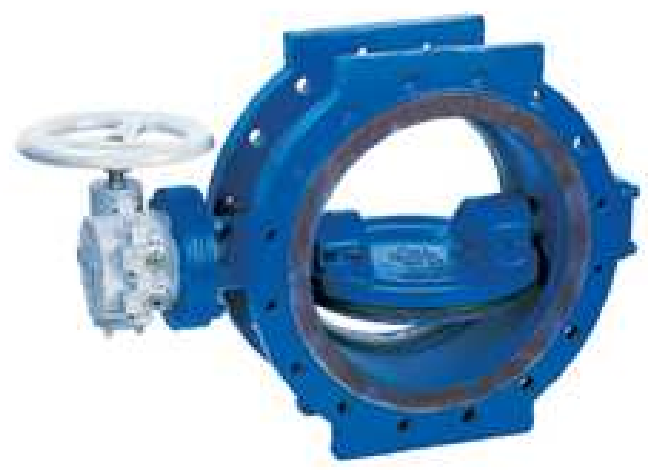

Figura 1: Válvula Borboleta

Como características principais da válvula Borboleta que afetam a capacidade de compressores podemos ver as seguintes:

- Geração de perda de carga, mesmo que pequenas, para que seja possível efetuar seu controle reduzindo assim a pressão de sucção na alimentação de compressores e reduzindo assim sua capacidade de compressão, por passar a operar em outro ponto da curva de performance;

- Turbilhonamento do fluido após a válvula e este fluido turbilhonado deve ser estabilizado pelos rotores prejudicando assim a performance do conjunto rotativo devido a forma de recebimento do gás para compressão. Conforme representado na Figura 2.

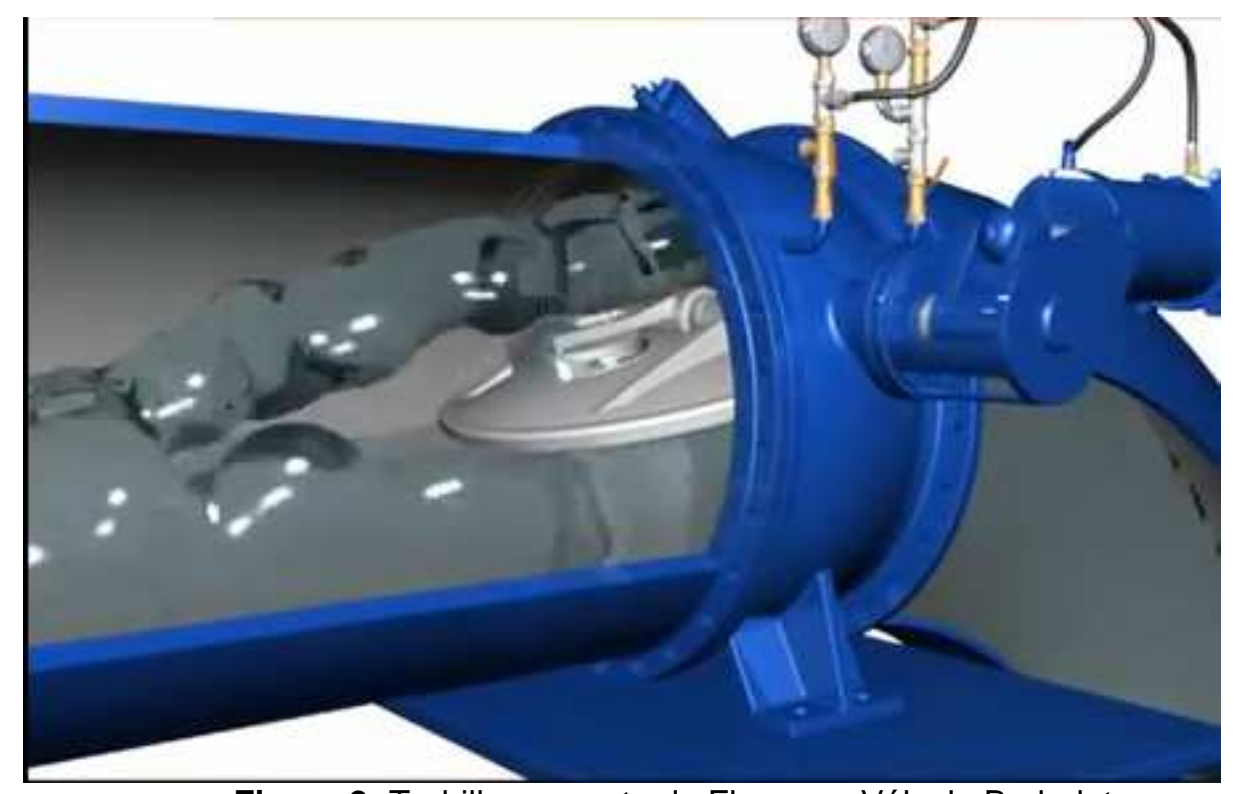

Figura 2: Turbilhonamento de Fluxo em Válvula Borboleta

Para correção destes problemas foi verificado que pode-se utilizar em substituição uma válvula tipo "Inlet Guide-Vane" que opera por meio de laminas que geram baixíssima perda de carga para o fluido e também fornece uma estabilização do fluido por meio de suas várias laminas de operação, conforme pode ser verificado pela figura 3 , e exemplos de estabilização de fluxo pela figura 4. 

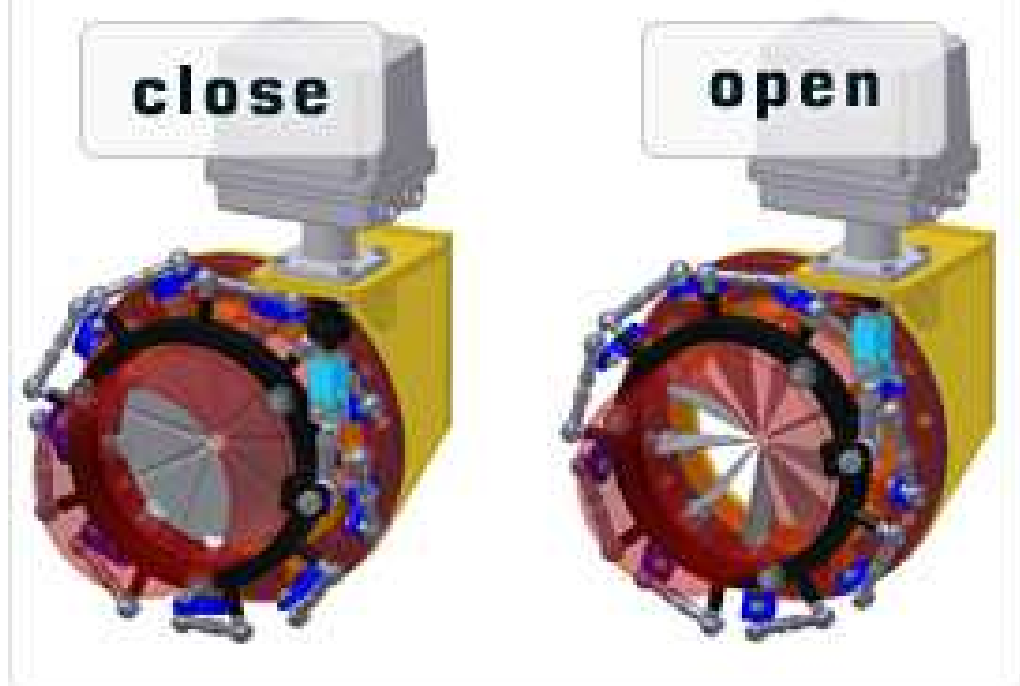

Figura 3: Exemplo de Válvula Inlet Guide-Vane

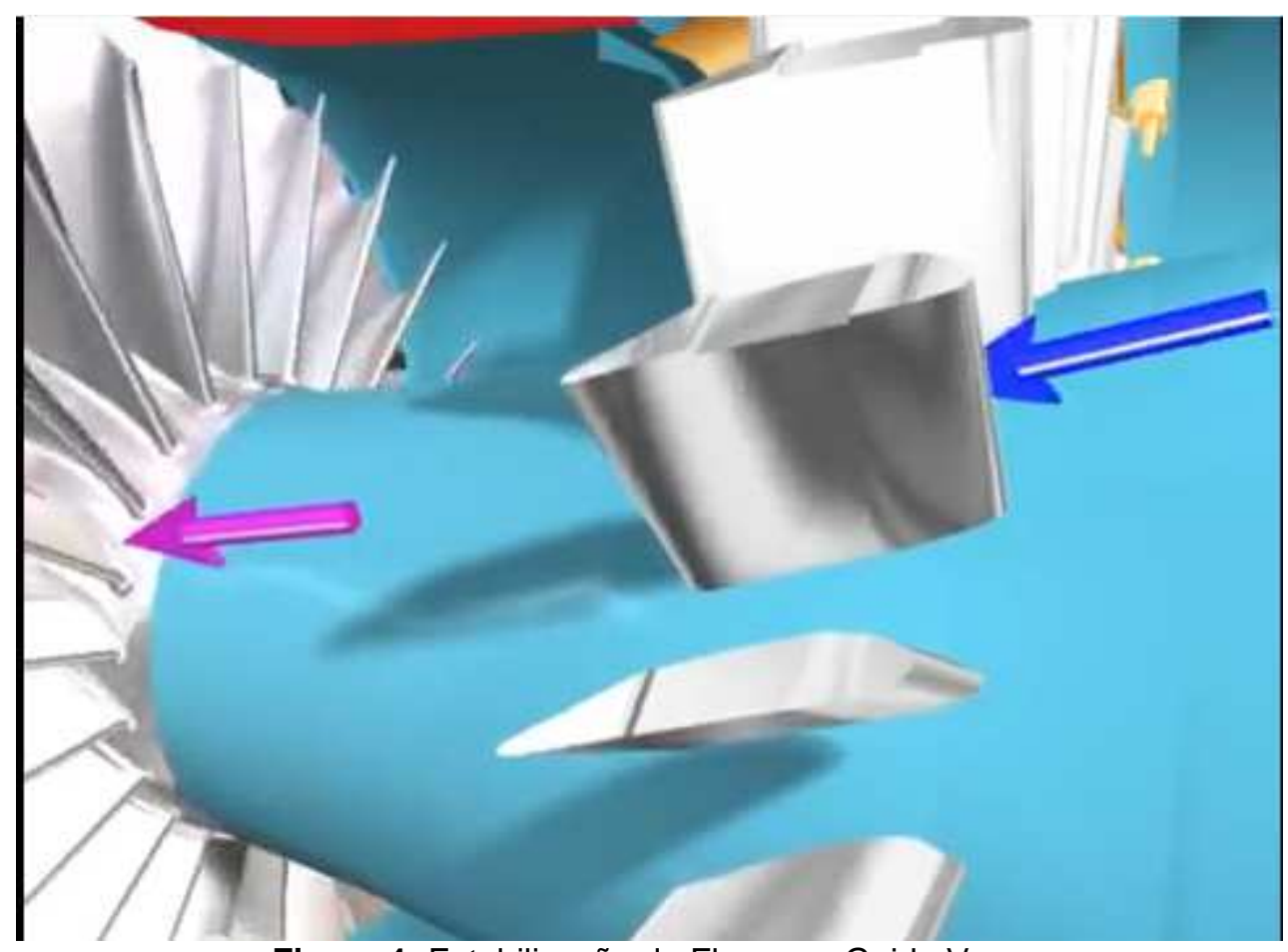

Figura 4: Estabilização de Fluxo por Guide Vane

\subsection{Objetivo}

O objetivo final do projeto é de elevar a capacidade de compressão.

Com base em cálculos e simulações foi estimado uma elevação de 4\% na capacidade de compressão ao substituir o sistema de alimentação. 


\section{RESULTADOS E DISCUSSÃO}

Apenas ao substituir a válvula borboleta de 16" por uma "Guide-Vane" diretamente na sucção do $1^{\circ}$ estágio do compressor rotativo foi possível elevar a capacidade de compressão em 3,8\%, conforme informações apresentadas abaixo:

Pressão Sucção:

Pressão de Descarga:

Temperatura de Alimentação:

Capacidade de Compressão:

Consumo de Energia Elétrica:

Número de Estágios:

Eficiência Adiabática:

\begin{tabular}{|c|c|c|}
\hline Antes & Após & \\
\hline 15,5 & 15,9 & psia \\
\hline 102 & 102 & psia \\
\hline 20 & 20 & ${ }^{\circ} \mathrm{C}$ \\
\hline 15.313 & 15.78 & $7 \mathrm{Nm}^{3 /}$ \\
\hline 1712 & 1.640 & $\mathrm{KW} / \mathrm{h}$ \\
\hline ? & 3 & \\
\hline 60 & 73 & $\%$ \\
\hline
\end{tabular}

Porém além de conseguir a elevação da capacidade de compressão é possível observar que o consumo de energia elétrica do compressor foi reduzido em 4,2\% mesmo operando com vazão superior, representando que a alimentação do primeiro estágio com fluido sem turbilhonamento a performance do sistema é muito mais eficiente do que a operação com uma válvula de controle simples.

\section{CONCLUSÃO}

Com a realização deste projeto foi Elevar a Vazão de Nitrogênio gás fornecido reduzindo o consumo de energia elétrica do conjunto compressor com baixo nível de investimento e tempo de parada do equipamento para instalação. Mesmo sendo um equipamento bastante antigo foi possível obter uma melhora significativa em sua performance sem qualquer alteração em intercoolers ou mesmo no sistema rotativo de compressão.

Com este projeto também foi possível identificar outras possibilidades de réplica dentro de unidades Praxair.

\section{Agradecimentos}

Agradecemos em especial aos Srs. Lucas Machado (Supervisor de Produção) e Vanderlei Gindro (Gerente de Unidade) que muito contribuíram na implementação do primeiro projeto.

\section{BIBLIOGRAFIA}

1 UNIISIM Process Modeling Software

2 Smith JM, Van Ness HC, Abbott MM. Introduction to chemical engineering thermodynamics. 7th Edition. 